\title{
Accuracy and reproducibility of low dose insulin administration using pen-injectors and syringes
}

\author{
M G Gnanalingham, P Newland, C P Smith
}

\begin{abstract}
Many children with diabetes require small doses of insulin administered with syringes or pen-injector devices (at the Booth Hall Paediatric Diabetic Clinic, $20 \%$ of children aged $0-5$ years receive 1-2 $U$ insulin doses). To determine how accurately and reproducibly small doses are delivered, 1, 2, 5, and $10 \mathrm{U}$ doses of soluble insulin $(100 \mathrm{U} / \mathrm{ml})$ were dispensed in random order 15 times from five new NovoPens $(1.5 \mathrm{ml})$, five BD-Pens $(1.5 \mathrm{ml})$, and by five nurses using $30 \mathrm{U}$ syringes. Each dose was weighed, and intended and actual doses compared. The two peninjectors delivered less insulin than syringes, differences being inversely proportional to dose. For $1 \mathrm{U}$ (mean (SD)): 0.89 (0.04) U (NovoPen), 0.92 (0.03) U (BD-Pen), $1.23 \quad(0.09)$ U (syringe); and for $10 \mathrm{U}$ : $9.8(0.1) \mathrm{U}$ (NovoPen), 9.9 (0.1) U (BD-Pen), 10.1 (0.1) U (syringe). The accuracy (percentage errors) of the pen-injectors was similar and more accurate than syringes delivering 1 , 2, and $5 \mathrm{U}$ of insulin. Errors for $1 \mathrm{U}$ : 11(4)\% (NovoPen), 8(3)\% (BD-Pen), $23(9) \%$ (syringe). The reproducibility (coefficient of variation) of actual doses was similar $(<7 \%)$ for all three devices, which were equally consistent at underdosing (pen-injectors) or overdosing (syringes) insulin. All three devices, especially syringes, are unacceptably inaccurate when delivering $1 \mathrm{U}$ doses of insulin. Patients on low doses need to be educated that their dose may alter when they transfer from one device to another. (Arch Dis Child 1998;79:59-62)
\end{abstract}

Keywords: pen-injector device; insulin syringes; insulin administration; low dose insulin

Department of

Paediatrics, Booth

Hall Children's

Hospital, Charlestown

Road, Blackley,

Manchester M9 2AA,

UK

M G Gnanalingham

C P Smith

Department of Clinica Biochemistry, Booth

Hall Children's

Hospital

P Newland

Correspondence to: Dr Smith

Accepted 3 February 1998 racy and precision using these devices should be recognised.

The limitations of professionals and patients attempting to draw up small doses of insulin into syringes are well recognised,,${ }^{12}$ inaccuracies being inversely proportional to the prescribed dose of insulin. ${ }^{1}$ Casella et al concluded that insulin injections of less than $20 \mu \mathrm{l}$ (2 U of U100) administered by syringe had an unacceptably large error. ${ }^{2}$ Similar information about pen-injector devices is not readily available, although one report found that the NovoPen 1 delivered $2 \mathrm{U}$ very accurately. ${ }^{3}$

To establish a policy for the administration of small doses of insulin, we compared the accuracy and reproducibility of administering small doses of insulin using two pen-injector devices and $30 \mathrm{U}$ insulin syringes.

\section{Methods}

To determine how frequently children require insulin doses of $\leqslant 5 \mathrm{U}$, the insulin regimen and individual doses used by children attending the Booth Hall Paediatric Diabetic Clinic were collected from their last outpatient visit. The children's age, sex, and duration of disease were recorded, and the device used (peninjector or syringe) for insulin injection was noted.

To determine how accurately and reproducibly two pen-injector devices deliver small doses of insulin, five new NovoPens $(1.5 \mathrm{ml})$ (NovoNordisk Pharmaceuticals) and five new BD-Pens (1.5 ml) (Becton Dickinson, Oxford, UK) with $29 \mathrm{G}$ needles (BD microfine) were used to deliver Humulin S (Eli Lilly, Basingstoke, Hants, UK) and Human Actrapid (NovoNordisk Pharmaceuticals, Crawley, West Sussex, UK) insulin, respectively. The $1.5 \mathrm{ml}$ insulin cartridges $(100 \mathrm{U} / \mathrm{ml})$ were left at room temperature for two hours before use. Before the sequence of measurements was made from each cartridge, an "air shot" was performed and $5 \mathrm{U}$ insulin was wasted. From each pen, 1, 2,5 , and $10 \mathrm{U}$ doses were expelled in random order 15 times, and the mean was used in subsequent analyses. All measurements were performed by a single investigator (MG) who waited 10 seconds after depressing the plunger each time to ensure that all the dialled dose was expelled. Each dose of insulin was deposited onto a polystyrene weighing container and was weighed immediately using an analytical balance (Avery Berkel FA214 balance; Avery Berkel Ltd, Shirley Institute, Manchester, UK) which has an accuracy of $0.0001 \mathrm{~g}$ and a reproducibility of $\leqslant \pm 0.0001 \mathrm{~g}$. The balance has an autocalibration facility, and was zeroed before the next dose of insulin was deposited and weighed. 
For comparison, five paediatric nurses who regularly administered insulin, used $30 \mathrm{U}$ insulin syringes with $29 \mathrm{G}$ needles (BD microfine) to draw up the same doses $(1,2,5$, and $10 \mathrm{U})$ of soluble insulin $(100 \mathrm{U} / \mathrm{ml})$ in random order 15 times. The vials of insulin were left at room temperature for two hours before use. Individual doses were expelled and weighed as previously described and the nurses were unable to view the results.

To study the pen-injector devices further, we considered whether the device or the insulin cartridge was the main source of any error. The BD-Pen and the NovoPen that had the lowest percentage error during the initial experiment were selected for further study. Following appropriate air shots, $5 \mathrm{U}$ of soluble insulin were dispensed and measured repeatedly until each insulin cartridge was emptied. Measurements were made using five cartridges of Humulin S and Human Actrapid insulin in the BD-Pen and NovoPen, respectively. For the purposes of analysis, each cartridge was divided into first, second, third, and fourth quarters, and there was an average of seven measurements from each of the quarters.

To validate the methodology that formed the basis of this study, $10 \mu \mathrm{l}$ of distilled water or $10 \mu \mathrm{l}$ of soluble insulin was dispensed 15 times using a laboratory pipette $(10 \mu \mathrm{l}$ Gilson Microman Bio-pipette; Villiers-le-bel, France) and was weighed as described previously. Aliquots of water had a mean (SD) weight of 0.01001 $(0.00027) \mathrm{g}$ and insulin samples weighed $0.00963(0.00021) \mathrm{g}$. The coefficient of variation for the method was $<3 \%$, and for the purposes of this study it was assumed that $10 \mathrm{U}$ of insulin $(10 \mu \mathrm{l})$ weighed $0.01 \mathrm{~g}$.

Dose accuracy and reproducibility were defined as follows:

$$
\begin{aligned}
& \text { intended dose- } \\
& \text { Accuracy }(\% \text { error })=\frac{\text { actual dose dispensed }}{\text { intended dose }} \times 100 \% \\
& \begin{array}{l}
\text { Reproducibilty } \\
\text { (coefficient of } \\
\text { variation) }
\end{array}=\frac{\begin{array}{c}
\text { standard } \\
\text { deviation of mean }
\end{array}}{\begin{array}{c}
\text { mean of actual dose } \\
\text { dispensed }
\end{array}} \times 100 \%
\end{aligned}
$$

All results were presented as means (SD) unless otherwise stated. Data were analysed by two factor ANOVA to determine population differences and by post hoc Duncan's multiple range test to detect intergroup variation. The interaction term states the relation between the device used and the intended dose of insulin. A probability of $<0.05$ was considered significant.

\section{Results}

One hundred and twelve children ( 64 boys and 48 girls) attended the clinic. Their mean (SD) age was $11.51(4.21)$ years and duration of disease 4.48 (3.52) years. Insulin was administered twice daily (101 children), once daily (seven children) or four times daily (three children). One girl who had autoimmune enteropathy received subcutaneous insulin once daily and insulin by intravenous infusion overnight while she received total parenteral nutrition. Twenty six of the 112 children were adminis-
Table 1 Doses of insulin delivered by two pen-injector devices and $30 \mathrm{U}$ insulin syringes

\begin{tabular}{llll}
\hline \multirow{2}{*}{$\begin{array}{l}\text { Intended } \\
\text { dose }\end{array}$} & \multicolumn{3}{l}{ Mean (SD) delivered dose $(\mathrm{U})$ (range) } \\
\cline { 2 - 4 } & NovoPen & BD-Pen & 30 U syringe \\
\hline $1 \mathrm{U}$ & $0.89(0.04)$ & $0.92(0.03)$ & $1.23(0.09)^{\star}$ \\
& $(0.85-0.95)$ & $(0.87-0.95)$ & $(1.16-1.37)$ \\
$2 \mathrm{U}$ & $1.90(0.03)$ & $1.90(0.05)$ & $2.24(0.09)^{\star}$ \\
& $(1.85-1.93)$ & $(1.82-1.94)$ & $(2.15-2.35)$ \\
$\mathrm{U}$ & $4.87(0.03)$ & $4.87(0.07)$ & $5.18(0.06)^{\star}$ \\
& $(4.84-4.91)$ & $(4.77-4.94)$ & $(5.10-5.26)$ \\
$10 \mathrm{U}$ & $9.80(0.09)$ & $9.86(0.09)$ & $10.07(0.07)^{\star}$ \\
& $(9.72-9.94)$ & $(9.73-9.96)$ & $(9.97-10.14)$ \\
\hline
\end{tabular}

*At all intended doses, $30 \mathrm{U}$ syringes delivered significantly higher doses than the pen-injector devices $(\mathrm{p}<0.01)$.

tered one or more doses of $1-5 \mathrm{U}$ insulin and the other five received one or more doses of only $1-2 \mathrm{U}$. Of 15 children aged $0-5$ years, three were receiving doses of only 1-2 U. Peninjector devices were used by 101 children and appropriately sized insulin syringes by the other 11 children. Only one child was receiving self mixed insulin.

Table 1 shows the intended and actual doses of insulin delivered by the pen-injectors and syringes. The two pen-injector devices delivered significantly less insulin than did experienced nurses using $30 \mathrm{U}$ insulin syringes at all doses studied (pen-injectors $v$ syringes, $\mathrm{F}=151, \mathrm{p}<0.0001$; units of insulin, $\mathrm{F}=58160, \mathrm{p}<0.0001 ;$ interaction term, $\mathrm{F}=1, \mathrm{p}=0.4)$. There were no differences in the mean insulin dose delivered by NovoPens and BD-Pens, and both tended to underdose. Nurses using $30 \mathrm{U}$ syringes tended to overdose, particularly when attempting to deliver $1 \mathrm{U}(+34 \%$ and $+38 \%$ compared with NovoPens and BD-Pens, respectively) and $2 \mathrm{U}$ ( $+18 \%$ compared with both pen-injectors).

Figure 1 shows the percentage error (accuracy) and coefficient of variation (reproducibility) with which the pen-injector devices and $30 \mathrm{U}$ syringes delivered small doses of insulin. Over the dose range studied, both pen-injector devices performed similarly and had lower percentage errors overall than nurses using $30 \mathrm{U}$ syringes (pen-injectors $v$ syringes, $\mathrm{F}=130, \mathrm{p}<0.0001$ ). For 1,2 , and $5 \mathrm{U}$ insulin doses, the percentage error using syringes was greater than with the NovoPen and BD-Pen $(\mathrm{p}<0.01)$. With all three devices, the percentage error diminished with increasing doses of insulin: $1>2>5 \sim 10 \mathrm{U}$ (units of insulin, $\mathrm{F}=1.6, \mathrm{p}<0.2$; interaction term, $\mathrm{F}=29, \mathrm{p}<0.0001)$.

Figure 1B shows how reproducibly small doses of insulin can be delivered using the three devices, regardless of their accuracy. The coefficient of variation was similar for both pen-injector devices and for the $30 \mathrm{U}$ insulin syringes $(F=0.5, p=0.6)$-that is, they were equally consistent at under or overadministering insulin. With all three devices, the coefficient of variation diminished with increasing doses of insulin: $1>2>5 \sim 10 \mathrm{U} \quad(\mathrm{F}=52$, $\mathrm{p}<0.0001 ;$ interaction term, $\mathrm{F}=0.4$, $\mathrm{p}=0.9)$.

There were no differences in the $5 \mathrm{U}$ doses of insulin delivered from the four quarters of 

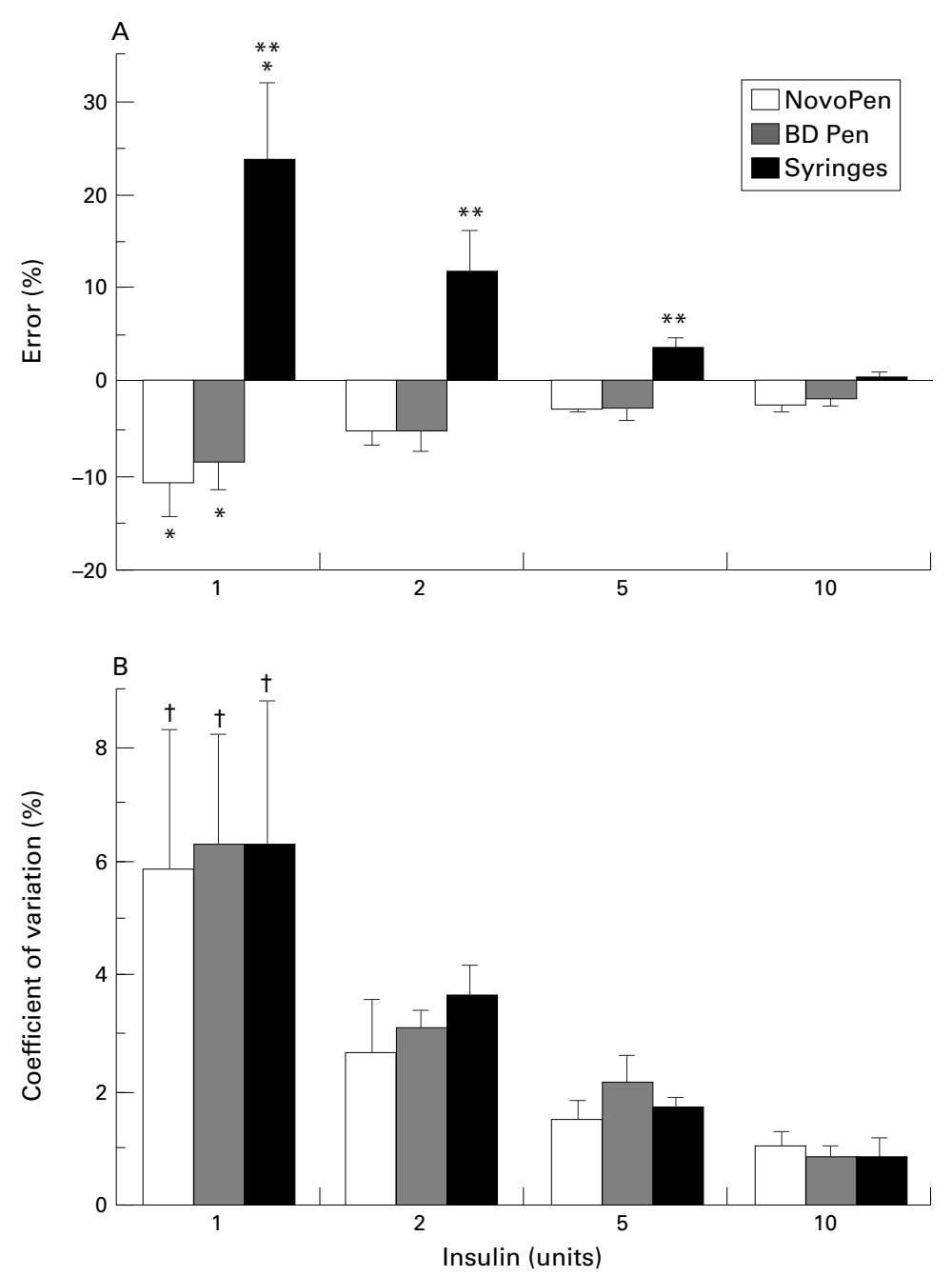

Figure 1 (A) Mean percentage error and (B) coefficients of variation (SD) when delivering 1,2, 5, and 10 U of insulin using five NovoPens, five BD-Pens, and five $30 \mathrm{U}$ syringes. For each device, a mean of 15 random measurements of each dose of insulin was calculated. ${ }^{\star} p<0.05,+p<0.01,1$ U differs from 2 , 5, or 10 U delivered by the same device; ${ }^{\star *} p<0.01,30$ U syringes differs from NovoPens and BD-Pens for the same dose of insulin. (Two factor ANOVA and post hoc Duncan's multiple range test.)

the cartridges in the NovoPens and BD-Pens $(\mathrm{F}=0.42, \mathrm{p}=0.7)$ (results not shown).

\section{Discussion}

This is the first study to compare the accuracy and reproducibility of pen-injectors and syringes delivering small doses of insulin. Previous studies have shown that delivering small doses of insulin using 30, 50, and $100 \mathrm{U}$ syringes is extremely inaccurate and imprecise with a human bias towards overadministration. ${ }^{12}$ Casella et al reported that paediatric nurses attempting to deliver $0.5,1.0$, and 2.0 $\mathrm{U}$ insulin resulted in delivered doses of 0.975 (0.315), 1.638 (0.376), and 2.153 $(0.435) \mathrm{U}$, respectively ${ }^{2}$; an overdose of $95 \%$, $64 \%$, and $7.5 \%$, respectively. They concluded that insulin injections of less than $20 \mu \mathrm{l}$ (2 U of $\mathrm{U} 100 / \mathrm{ml}$ ) had an unacceptably large error when administered by syringe. Our results concurred with this, the percentage errors of paediatric nurses drawing up $1 \mathrm{U}$ and $2 \mathrm{U}$ doses using $30 \mathrm{U}$ insulin syringes being $23 \%$ and $12 \%$, respectively. It is interesting that parents could draw up insulin more accurately

\section{Key messages}

- Insulin doses of $<2 \mathrm{U}$ are administered inaccurately by syringe and pen-injector devices

- The reproducibility (coefficient of variation) of actual doses was similar $(<7 \%)$ using two pen-injector devices (NovoPen and BD-Pen), and $30 \mathrm{U}$ syringes

- Pen-injectors underdose and nurses using $30 \mathrm{U}$ syringes overdose insulin

- Transferring patients on low insulin doses from syringe to pen-injector may result in a significant dose change

than the nurses could. ${ }^{2}$ Bell et al reported much higher percentage errors ( $45 \%$ for $2 \mathrm{U,}, 20 \%$ for $5 \mathrm{U})$ probably because their study involved self mixing regular and isophane insulins, which were shown to be far less accurate, and the participants were not allowed to overdraw the syringe and evacuate the excess. ${ }^{1}$ Disappointingly, use of the narrower bore $30 \mathrm{U}$ syringe instead of $50 \mathrm{U}$ and $100 \mathrm{U}$ syringes did not improve the accuracy or precision of professionals, ${ }^{12}$ but in patients there was a small but significant improvement at low doses. $^{2}$ Because $30 \mathrm{U}$ syringes were better or certainly no worse at delivering small doses, we confined ourselves to the $30 \mathrm{U}$ syringe in this study.

Information about the accuracy and precision of pen-injector devices delivering small doses is not readily available, although Gordon and colleagues ${ }^{3}$ reported that the accuracy of NovoPen 1 delivering $2 \mathrm{U}$ was good, having a percentage error of $2.8 \%$. This compares with percentage errors of $5.1 \%$ for $2 \mathrm{U}$ doses administered using the NovoPen 1.5 or the BD-Pen 1.5 in our study. Our results demonstrated that the accuracy and reproducibility of the NovoPens and BD-Pens were similar and both improved as the dose increased. Both pen-injectors were significantly more accurate than $30 \mathrm{U}$ insulin syringes at doses of 1,2 , and $5 \mathrm{U}$ but, perhaps surprisingly, the variability of actual doses administered was very similar between the pen devices and syringes. Our results demonstrated that when using syringes there was a human bias towards overdosage while pen-injector devices tended to underdose. This is important if one is considering transferring patients from syringe to pen or vice versa. An intended dose of $1 \mathrm{U}$ may be an actual dose of $0.89 \mathrm{U}$ by pen or $1.23 \mathrm{U}$ by syringe, so changing from one device to the other would amount to a change in dose of $38 \%$.

This study reflects favourably on peninjector devices in terms of their accuracy, and the BD-Pen and NovoPen were equally good. It must be remembered, however, that there are numerous opportunities to introduce error when using such devices in clinical practicefor example, when patients do not remove the needle between injections or do not do an air shot before injecting. ${ }^{4}$ Also, insulin is delivered 
more slowly from cartridges than syringes because of the compressible elements of the cartridge. ${ }^{4}$ If patients fail to leave the needle in place for the recommended five or 10 seconds after pushing down the plunger (when using $12.7 \mathrm{~mm} 29 \mathrm{G}$ or $8 \mathrm{~mm} 30 \mathrm{G}$ needles, respectively), they may administer less insulin than intended.

We tried to determine whether the devices or the insulin cartridges were the most important source of error for the pen-injectors. By comparing the doses delivered from the four quarters of the cartridge, we attempted to detect errors created by defects in the glass cylinders that make up the cartridges. No differences were found between the doses delivered from the different parts of the cartridge, but we acknowledge that we used fairly crude methodology. Becton Dickinson informed us that the glass cartridges were probably the most important source of dosage variability (personal communication).

Added to the considerable inaccuracies and variability involved in administering small volumes of insulin, there are many other factors that affect the absorption and hence the activity profile of insulin. The reported intraindividual and interindividual variation of absorption is about $25 \%$ and $50 \%$, respectively, ${ }^{56}$ and children are at high risk of receiving inadvertent intramuscular injections, ${ }^{78}$ which leads to faster absorption. ${ }^{9} 10$

In conclusion, administering small volumes of insulin is fraught with problems, and yet in this study $20 \%$ of children aged $0-5$ years were receiving doses of 1-2 U (10-20 $\mu$ l of U100/ $\mathrm{ml})$. The incidence of diabetes in children aged $0-4$ years is increasing by $11 \%$ per year ${ }^{11}$ at a time when we know we should strive for normoglycaemia. ${ }^{12}$ However, tight control results in a significant risk of severe hypoglycaemia, ${ }^{12}$ which is potentially more harmful in this age group. ${ }^{13}$ Any dosing error will increase this risk and so perhaps we should consider requesting the reinstatement of the more dilute U40 insulin, which is still available in some countries. This would enable parents to deliver small doses more accurately and precisely. Alternatively, we should consider giving once rather than twice daily injections to children whose evening dose is less than $2 \mathrm{U}$, and possibly to those receiving $2 \mathrm{U}$ doses.

We are grateful to Sue Bennett (diabetes specialist nurse) and Franscine Radivan (senior pharmacist) for their help; as well as to Eli Lilly and Co and Novo Nordisk Pharmaceuticals Ltd for supplying the insulin.

1 Bell DSH, Clements RS, Perentesis G, Roddam R, Wagenknecht L. Dosage accuracy of self-mixed vs premixed insulin. Arch Intern Med 1991;151:2265-9.

2 Casella SJ, Mongilio RN, Plotnick LP, Hesterberg P, Long CA. Accuracy and precision of low-dose insulin administration. Pediatrics 1993;91:1155-7.

3 Gordon D, Wilson M, Paterson KR, Semple CG. An assessment of the accuracy of NovoPen 1 delivery after prolonged ment of the accuracy of NovoPen 1 delic Medicine 1990;7:364-6.

4 Ginsberg BH, Parkes JL, Sparacino C. The kinetics of insuGinsberg BH, Parkes JL, Sparacino C. The kinetics of insu-
lin administration by insulin pens. Horm Metab Res 1994;26:584-7.

5 Galloway JA, Spradlin CT, Nelson RL, Wentworth SM, Davidson JA, Swarner JL. Factors influencing the absorption, serum insulin concentration, and blood glucose responses after injections of regular insulin and various insulin mixtures. Diabetes Care 1981;4:366-76.

6 Kolendorf K, Aaby P, Westergaard S, Deckert T. Absorption effectiveness and side-effects of highly purified porcine NPH-insulin preparations. Eur f Clin Pharmacol 1978;14: $117-24$

7 Smith CP, Sargent MA, Wilson BPM, Price DA. Subcutaneous or intramuscular insulin injections. Arch Dis Child 1991;66:879-82.

8 Polak M, Beregszaszi M, Belarbi N, Benali K, Hassan M, Czernichow $\mathrm{P}$, et al. Subcutaneous or intramuscular injections of insulin in children. Diabetes Care 1996;19:1434-6.

9 Frid A, Gunnarsson R, Guntner P, Linde B. Effects of accidental intramuscular injection on insulin absorption in dental intramuscular injection on

10 Spraul M, Chantelau E, Koumoulidou J, Berger M. Subcuaneous or nonsubcutaneous injection of insulin. Diabetes Care 1988;11:733-6.

11 Gardner SG, Bingley PJ, Sawtell PA, Weeks S, Gale EAM, the Bart's-Oxford Study Group. Rising incidence of insulin dependent diabetes in children aged under 5 years in the Oxford region: time trend analysis. BMf 1997;315:713-17.

12 The Diabetes Control and Complications Trial Research Group. The effect of intensive treatment of diabetes on the development and progression of long-term complications in insulin-dependent diabetes mellitus. N Engl F Med 1993; 329:977-86.

13 Gold AE, Frier BM. Hypoglycaemia-practical and clinical implications. In: Kelnar $\mathrm{CJH}$, ed. Childhood and adolescent diabetes. London: Chapman \& Hall Medical, 1995:351-66. 